\title{
Familial idiopathic steroid-resistant nephrotic syndrome
}

INSERM

\section{Source}

INSERM. (1999). Orphanet: an online rare disease and orphan drug data base. Familial idiopathic steroid-resistant nephrotic syndrome. ORPHA:656

Familial idiopathic steroid-resistant nephrotic syndrome is characterized by a nephrotic syndrome with often early onset. 